\title{
WRITING TO LEARN MATHEMATICS
}

\author{
Luís Menezes, Ana M. Costa \\ Polytechnic of Viseu and CI\&DETS (PORTUGAL)
}

\begin{abstract}
This paper is a reflection on the potential of written communication for learning mathematics, considering in it the construction of mathematical knowledge and transversal skills, such as communication, reasoning and problem solving. Based on the research carried out, we present and discuss three contexts that can contribute to the promotion of written communication: (i) Resolution of challenging problems; (ii) Description of images based on graphic humour about Mathematics; and (iii) Production of stories about Mathematics. The examples presented, from students at the end of primary school, indicate that students are able to produce written mathematical text, mobilizing their knowledge and creativity.
\end{abstract}

Keywords: Mathematics, language, written communication, classroom, tasks.

\section{INTRODUCTION}

In this paper, it is held that the written communication is important for the learning Mathematics. We begin by reflecting on the relationship between language, thinking and learning. Then, we focus our attention on language and on language skills, like speaking, listening, writing and reading, while aware that the first two of the aforementioned skills start to be learned informally by children since they are born, and then expanded through formal education, while the last are only formally taught at school. The mother tongue, as one of the school subjects, plays a pivotal role in the development of these language skills, essential for the learning of all other subjects, but none of the others disciplines should disregard this role of improving the language skills at issue.

In this paper, we focus specifically on one of the school subjects, with a substantial importance in most school systems throughout the world, Mathematics. This subject has characteristics that make it special in terms of communication, given that it has its own code of symbols that can be combined, in very varying degrees, with verbal language to express ideas. In this sense, we also focus our interest on written communication, aiming to show that the learning of Mathematics, which comprises mathematical knowledge, but also transversal skills, such as mathematical communication, implies the performance of diverse and challenging mathematical tasks. This student activity leads to thinking in a divergent and creative way and to communicating that thought to others (teachers and colleagues).

To illustrate the kind of tasks that can be used for written communication as an important element of student learning, we present three contexts: (i) Written records to solve a mathematical task and support for collective discussion; (ii) Written records resulting from a task based on graphic humour; and (iii) Writing a story about Mathematics.

\section{LANGUAGE, THINKING AND LEARNING}

The relationship between the development of language and the development of thinking and learning has been studied, for a long time, by many authors, namely from fields such as Psychology (Lev Vigotski, Jean Piaget), Linguistics (Noan Chomsky) or Philosophy (Ludwig Wittgenstein, John Searle). For Vigotski (1998), "the relationship of thought to word is not a thing but a process, a movement from thought to word and from word to thought." (p. 156). The author adds that this "relationship of thought to word is a vital process that involves the birth of thought in the word. Deprived of thought, the word is dead (...) thought that is not embodied in the word remains a shadow." (p. 190). Verbal thought is an important construct in VigotsKi' theory, in which the development of language contributes to the development of thought and this to the development of language.

Bruner also highlights the role of culture, stating that there is a mutual influence between thought and language, maintaining that "language and culture cannot be conceptually separated from one another: culture is the medium of language and language the vehicle of culture" (Bakhurst \& Shanker, 2001, p. 10). 
These ideas about the relationship between language, thinking and learning influenced academics concerned with teaching models. In this paper, we are interested in the work of some authors who conceive the use of language to teach mathematics as a process of social interaction (Bauersfeld, 1992, 1994; Jung \& Schütte, 2018; Guerreiro, Tomás-Ferreira, Menezes \& Martinho, 2015; Güven \& Dede, 2017; Muthelo \& Chigonga, 2018).

For the interactionist program, "learning describes a process of personal life formation, a process of an interactive adapting to a culture through active participation (which, in parallel, reversely constitutes the culture itself) rather than a transmission of norms, knowledge, and objectified items" (Bauersfeld, 1994 , p. 128) and "teaching describes the attempt to organize an interactive and reflexive process, with the teacher engaging in a constantly continuing and mutually differentiating and actualizing of activities with the students, and thus the establishing and maintaining of a classroom culture" (Bauersfeld, 1994, p. 129).

In this teaching - learning framework, Bauersfeld (1994) stresses that in relation to language in the mathematics classroom, we can reach different practices "depending on whether languaging is taken as the use of an objectively existing body of language, of the storehouse of societal knowledge and prepared meanings, or whether languaging is understood as a social practice of orienting" (p. 141).

In these classes, student activity is triggered by challenging tasks, which can be problems, investigations or explorations, which are placed by the teacher and which are usually solved by students in small groups. These tasks originate written records that facilitate the students' reasoning when solving the task, and who support the collective discussion that comes next (Menezes, Oliveira \& Canavarro, 2015; Planas, Morgan \& Schütte, 2018; Stein, Engle, Smith \& Hughes, 2008).

Written communication in mathematics classroom can take different forms, resulting from the combination of the mother tongue, the symbolic language of Mathematics and also the representations such as tables, diagrams and drawings. Depending on the culture of the mathematics classroom and the students' school attendance grade, this combination can result in very varied written products. These can be more or less formal, more or less detailed, and with more or less explanations and justifications.

Research has pointed out the main benefits of writing to learn Mathematics, namely: Develop mathematical understanding; Promote reflection; Produce records for study; Increase self-confidence when communicating with others; Generate positive attitudes towards Mathematics; Support the assessment of mathematical learning (self and by the teacher) (Flores \& Brittain, 2003; Martin, Polly \& Kissel, 2017; Morgan, 2002).

Morgan (2002) notes that "writing in mathematics classrooms (...) is not a simple matter. Nevertheless, recent changes in the mathematics curriculum have encouraged a wider range of classroom activities involving both oral and written language" (p. 241). Thus, we believe the following question to be relevant: How to develop written communication in mathematics classes? Some authors present strategies to develop, in Mathematics, written communication, namely: (i) Solve problems; (ii) Describe images; (iii) Write stories about Mathematics; (iv) Explain why something works; (v) Describe what one has done; (vi) Produce written reflections; and (vi) Create a wall journal/newspaper (Burton \& Morgan, 2000; Martin, Polly \& Kissel, 2017; Morgan, 2002).

In this text, we discuss, based on research carried out by us, the written productions made by students at the end of primary education (grades 4 to 6 ) using the first three strategies: Solve problems, describe images and write stories about Mathematics.

The task presented to exemplify the first strategy is challenging, having characteristics of an investigation. The second exemplified strategy - describe images - is based on humorous comic strips on Mathematics. The strip presented is part of a book of mathematical tasks that have the same nature: "Humour to learn Mathematics: Mathematical tasks to laugh and learn" (Menezes et al., 2020).

The tasks based on comic strips have been pointed out with potential to develop written communication in Mathematics, also with the development of problem solving, reasoning and learning mathematical concepts (Guitart, 2012; Menezes \& Costa, 2020; Menezes et al., 2019; NCTM, 2007, 2013). All tasks start with this request: "Describe the situation presented in the comics. Why can the situation be funny?". We present one of the tasks, "Geometry, what I want you for!", used in the classroom (Figure 1): 


\section{FOXTROT}
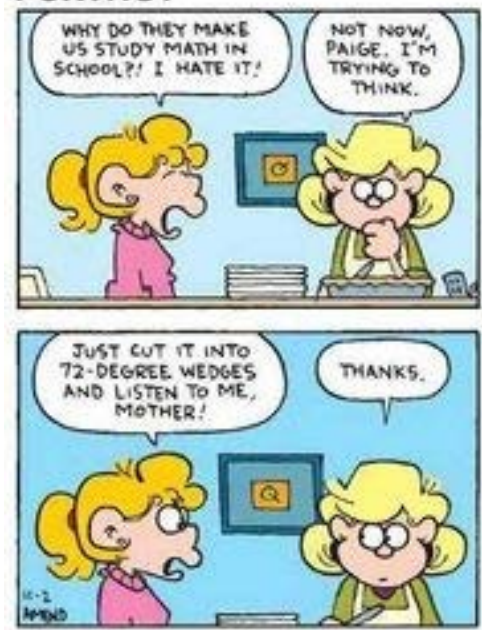
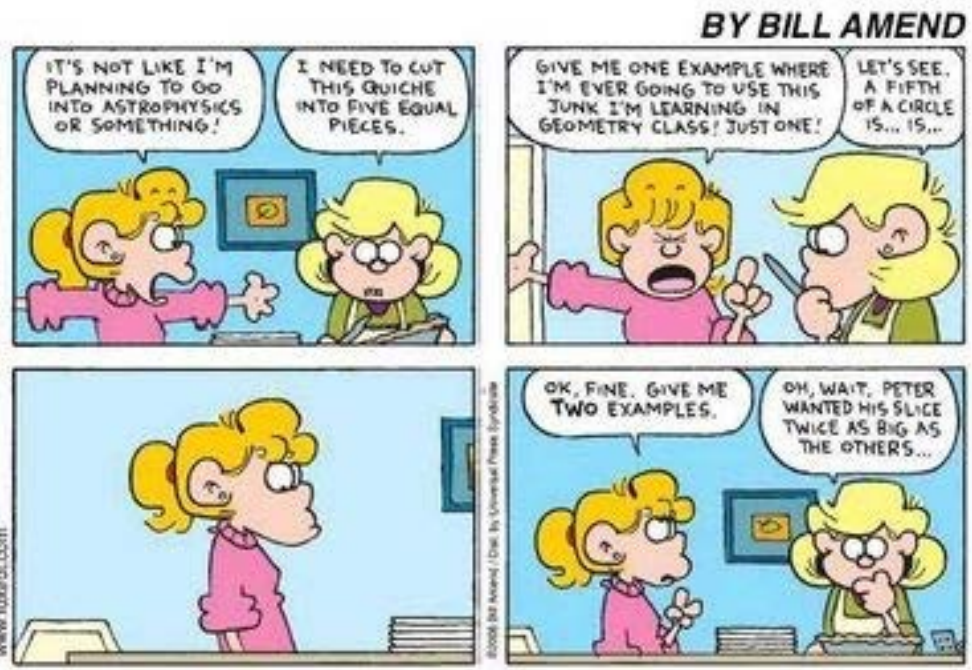

1. Describe the situation presented in the comics. Why can the situation be funny?

2. Is Paige right about the usefulness of mathematics?

3. What do you think about Paige's solution to the mother's problem?

4. How to solve the problem posed in the last vignette?

Figure 1. Task "Geometry, what I want you for!" (Menezes et al., 2020, p. 11).

As noted, after describing the strip, the authors present questions / problems that involve different mathematical concepts. The tasks aim to present and consolidate mathematical knowledge, leading students to use mathematics for laughing (Menezes et al., 2019).

To encourage students to write an answer to question 1, the book suggests four aspects to guide the description and facilitate the understanding of the situation, lead to laughter and to a most supported answer o the following questions:

- Environment (in what context / scenario do the events occur? What are the elements of the comic strip that make us identify this scenario?);

- Subjects (who are the characters? What is known about them? What do they represent?);

- Action (what happens?)

- Shock of expectations / unexpected ending (what causes humor? What is the circumstance that makes the situation funny?) (Menezes et al., 2020, p. 7).

The third strategy is writing stories about Mathematics. Writing stories about Mathematics can be a powerful strategy to promote writing in mathematics, leading students to learn, because: (i) human beings, and children in particular, like stories; and (ii) writing about Mathematics leads students to use and develop their mathematical knowledge. Research shows that students writing stories benefits from students reading, in this case, stories about Mathematics. In primary education, connecting the mother tongue taught as a school subject and Mathematics plays a very important role in reading and writing stories about Mathematics.

\section{PROMOTING WRITING IN MATHEMATICS}

In this section, we illustrate the three strategies previously indicated for promoting mathematical writing and contributing to the learning of Mathematics. 


\subsection{Solve problems: Cubes with Stickers}

In Menezes, Oliveira and Canavarro (2015), we find an illustration of writing in problem solving in Mathematics, with students of grade 4 . They are invited to solve the task, in small groups, a challenging task, entitled: "Cubes with stickers" (Figure 2):

\section{Cubes with Stickers}

Joana is building a game with cubes and stickers. She connects the cubes through one of its faces and forms a queue of cubes. Then she glues a sticker in each of the cube's faces. The figure shows the construction that Joana did with 2 cubes. In that construction she used 10 stickers.

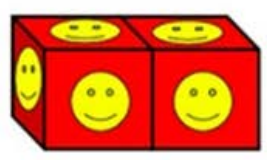

1. Find out how many stickers Joana used in a construction with:

1.1 Three cubes;

1.2 Four cubes;

1.3Ten cubes;

1.4 Fifty-two cubes.

2. Can you find out what is the rule that allows you to know how many stickers Joana used in a construction with any given number of cubes? Explain how you thinking

Figure 2. Task "Cubes with Stickers" (Menezes, Oliveira \& Canavarro, 2015, p. 312).

The groups of students solve the task and are told that they have to prepare a slide, with the solution, to present to the class. Figure 3 presents the solution of one of the groups to question 2, in which the rule's enunciation in natural language is written at the top. Students write: "The rule to find de number of stickers is to make the number of cubes ( $\times 4)$ sides of a cub and plus the two lateral faces as well" (Menezes, Oliveira \& Canavarro, 2015):

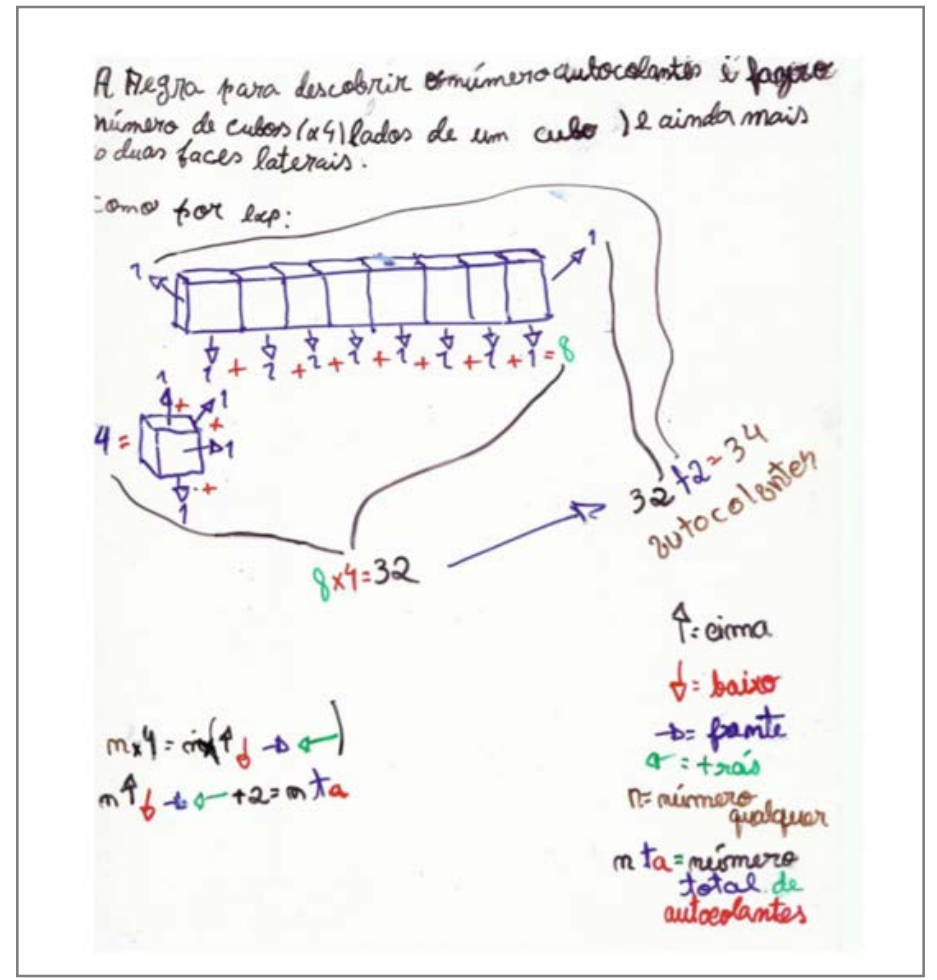

Figure 3. Register of a pair of students; question 2 (Menezes, Oliveira \& Canavarro, 2015, p. 315). 
This register reveals, in addition to the enunciation of the rule, the use of symbolic language of Mathematics and pictorial representations of the cubes (supported by the use of different colours to encode the different faces of the cube). This combination of written languages fulfills the role of organizing students' thinking and facilitating communication to the class, as shown in the following dialogue:

João: So, we... said that the "rule for discovering the number of stickers is to make the number of cubes that was requested times four sides, times four which are the four sides of the cube and even more the two side faces, plus adding the two lateral faces and we gave an example. In this case we have eight cubes here, each cube is represented here and then the side faces here, as we said above. So, we added, we added 8 more sides. Then we showed the cube here and then we made eight cubes times 4 sides will give $32 \ldots$

Boy: This is not clear....

Girl: Well, this is very confusing.

João: I 'll explain better... there are eight cubes, right? And we represented the four sides, front, back, up and down.

Teacher: If you want to exemplify. (Menezes, Oliveira \& Canavarro, 2015, p. 315)

This dialogue continues, and with the support of cubes, provided by the teacher, and the written record of the slide, the student is able to present the line of reasoning of his group, and make himself understood by his colleagues. This episode reveals the potential of mathematical writing to think and to communicate. Without the written record, most likely, João, the student who presented the resolution, would have more difficulty in presenting his thoughts to the class, without flaws in his explanatory procedure.

Although two students expressed their difficulty in understanding the resolution, the communication of the rule, supported by the scheme, was understood by most students. Still, the teacher suggested to João that he should make use of the cubes themselves as resources to support/illustrate the explanation.

Bearing in mind that this task was performed by 9- and 10-year-old students, the oral presentation of the rule, without being supported by written records, would certainly bring more difficulties to students.

\subsection{Describe images: the serious side of humour}

The task (Figure 1) was performed by grade 6 students, individually, at home and sent to the teacher by email (already during the pandemic period) (Menezes \& Costa, 2020). The answers to the various questions reveal a well-written and well-reflected text, only possible when students have the opportunity to read and reread.

In responding to question 1 "Describe the situation presented in the comics. Why can the situation be funny?", of the task "Geometry, what I want you for!", we note that the orientations of the description (environment, subjects, action, shock of expectations) has benefited the quality of the description (and the understanding of the comic situation).

1) Paige and her mother are two characters who are in the kitchen because the mother is trying to share a pie according to the request made to her, and is wearing an apron. On the strip, Paige is complaining because she considers that the mathematics that requires her to study at school, will not be useful to her in the future. The mother wasn't even paying attention to Paige, because she was worried about trying to share her pie. In Paige's thought, mathematics is not important and does not apply, except in a profession related to the area. But, unintentionally, she solves, for her mother, a mathematical problem of everyday life. She realized that by using mathematics, she has helped her mother. For this reason, she tries to disguise it, but, soon after, she is faced with another problem that she has to solve. The situation is funny because, without realizing it, she is already responding and helping her mother, using mathematics. (Student 11, Grade 6)

The answers to questions 2, 3 and 4 reveal that the description presented in question 1 helped the student.

2) Paige is not right because mathematics is important in everyday life, since we are confronted with it everywhere. 
3) The solution found is correct, because if the pie is in the shape of a circle, that has $360^{\circ}$. and if we divide it into 5 equal parts, each part will have $72^{\circ}$.

4) In order to ensure that Peter's slice is twice the size of others' slices, Paige's mother will have to divide $360^{\circ}$ by 6 , which is $60^{\circ}$ and then multiply by 2. Thus, she would have four slices with $60^{\circ}$ and Peter's slice would have $120^{\circ}$. (Student 11, Grade 6)

\subsection{Stories about Mathematics: a contest}

Writing stories about mathematics is not a task reserved for adults, writers of children's literature. This can be a task that can be performed by students, starting from the early years of school. The production of these texts promotes divergent thinking, develops creativity and consolidates the construction of mathematical knowledge.

For 13 years, we have run a children's literary contest, called "Once upon a time... with mathematics", in which hundreds of students have participated and in which we have already published 3 books, entitled "Stories... with Mathematics". Figure 4 presents the cover of the 3rd book, from which we extract an initial part of a story about Mathematics carried out by an 11-year-old child:

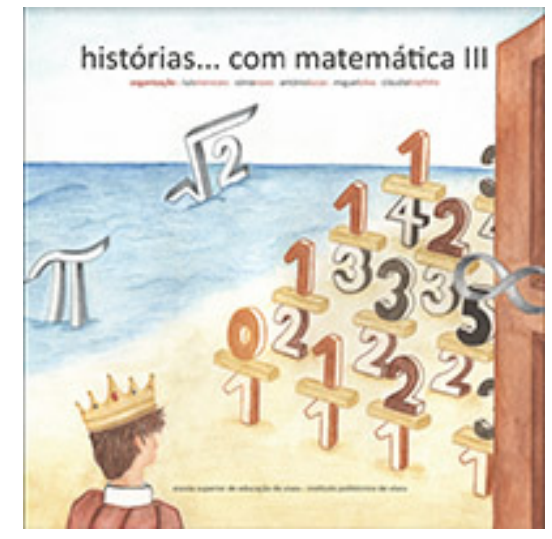

Figure 4. Cover of the book "Stories... with Mathematics III" (Edited by L. Menezes et al., 2015)..

In the story "Racism between the geometric figures", Melanie Antunes, a child at the time, uses her creativity, resorting to mathematical concepts from Geometry to send a message against racism. The story begins:

Once upon a time there was an equilateral triangle called Daniel. He had a large family with great intelligence. The family of equilateral triangles stood out from the other two due to the perfection in the measure of all its sides, because they measured exactly the same... which implied angles also with the same amplitude! They were regular polygons!!!!!!! Very perfect polygons, very balanced, and very elegant. Unusual conditions.

This equilateral triangle, we know not why, had a very beautiful daughter, Maria, whose appearance was nonetheless different from her father's. It had characteristics of right triangle and isosceles!!!!!!! (...) (Antunes, 2015, p. 47)

\section{FINAL REMARKS}

Writing to learn mathematics? This is the question that underlies our reflection, to which practically all mathematics teachers, adopting very different teaching models, would answer in the affirmative.

However, it is clear that it is very different for students to write out the solutions to exercises equals to so many others, using almost exclusively the symbolic language of Mathematics, or, on the other hand, to solve problems, describe images and produce stories about Mathematics.

The examples that we put forward in this paper regarding these last three contexts, reveal the richness of the students' writing and mathematical thinking (Menezes, Oliveira \& Canavarro, 2015). These records, in addition to promoting divergent thinking and creativity of students, are closer to contribute to meaningful learning (Bauersfeld, 1994; Flores \& Brittain, 2003; Jung, \& Schütte, 2018). 
In summary, the idea that we defend in this paper is that mathematics teachers should diversify the contexts in which they invite students to write in Mathematics. Finally, we must not forget that writing, unlike speech, is learned fundamentally from the moment students enter in school. Towards the fulfilment of this goal, all school subjects must contribute, namely Mathematics.

\section{ACKNOWLEDGEMENTS}

This work is funded by National Funds through the FCT - Foundation for Science and Technology, I.P., within the scope of the project $\operatorname{Ref}^{a}$ UIDB/05507/2020. Furthermore, we would like to thank the Centre for Studies in Education and Innovation (CI\&DEI) and the Polytechnic of Viseu for their support.

\section{REFERENCES}

[1] A. Flores \& C. Brittain, "Writing to reflect in a mathematics methods course", Teaching Children Mathematics, vol. 10, no. 2, pp. 112-119, 2003.

[2] A. Guerreiro, R. A. Tomás Ferreira, L. Menezes, \& M. H. Martinho, "Comunicação na sala de aula: A perspetiva do ensino exploratório da Matemática", Zetetiké, vol. 23, no. 4, pp. 279-295, 2015.

[3] C. Morgan, "Writing Mathematically: The Discourse of Investigation". London: Routledge, 2002.

[4] D. Bakhurst \& S. G. Shanker, "Introduction: Jerome's way" in Jerome Bruner: Language, culture and self (D. Bakhurst \& S. G. Shanker eds.), 1.-18, London: Sage, 2001.

[5] D. Muthelo \& B. Chigonga, "Attributes of Mathematics Enculturation: Sarah's Experiences in the Mathematics Classroom", Pedagogical Research, vol. 3, no. 1, 2018.

[6] H. Bauersfeld, "Theoretical perspectives on interaction in the mathematics classroom" in Didactics of Mathematics as a scientific discipline (R. Biehler, R. Scholz, R. Sträßer e B. Winkelmann eds.), 133-146, Dordrecht: Kluwer Academic Pub, 1994.

[7] H. Bauersfeld, "Integrating theories for mathematics education", For the Learning of Mathematics, vol. 12, no. 2, pp. 19-28, 1992.

[8] J. Jung \& M. Schütte, "An interactionist perspective on mathematics learning: conditions of learning opportunities in mixed-ability groups within linguistic negotiation processes", ZDM, vol. 50, no. 6, pp. 1089-1099, 2018.

[9] L. Burton \& C. Morgan, "Mathematicians Writing". Journal for Research in Mathematics Education. Vol. 41, no.4, pp. 429-453, 2000.

[10] L. Menezes \& A. M. Costa, " Graphic humor to promote mathematics learning", Proceedings of IRAJ International Conference, vol. 1, 1.-6, 2020.

[11] L. Menezes, H. Gomes, A. Ribeiro, A. P. Martins, P. Flores, F. Viseu, A. M. Oliveira, I. A. Matos, J. P. Balula, \& V. Delplancq, "Humor in Mthematics teaching: Tasks for the classroom". Viseu: ESE IPV, 2019.

[12] L. Menezes, H. Oliveira, \& A. P. Canavarro, "Inquiry-based mathematics teaching: The case of Célia" in Educational paths to Mathematics (U. Gellert, J. Gimenez Rodriguez, C. Hahn, S. Kafoussi, eds.), 305-321, Cham: Springer, 2015.

[13] L. Menezes, P. Flores, F. Viseu, H. Gomes, A. Ribeiro, A. P. Martins \& M. Guitart, Humor para aprender Matemática: Tarefas matemáticas para rir e aprender. Viseu: Litoprint ESEV, 2020.

[14] L. Menezes, S. Novo, A. Lucas, M. Silva \& C. Batista, "Histórias... com Matemática III". Viseu: Escola Superior de Educação de Viseu, 2015.

[15] L. S. Vigotski, Pensamento e linguagem. S. Paulo: Martins Fontes, 1998.

[16] M. Guitart, "Permitido reír... Estamos en clase El humor como recurso didáctico en aula de Estadística". Mendoza: National University of Cuyo, 2012.

[17] N. D. Güven \& Y. Dede, "Examining social and sociomathematical norms in different classroom microcultures: Mathematics teacher education perspective", Educational Sciences: Theory \& Practice, vol. 17, no. 1, 2017. 
[18] N. Planas, C. Morgan \& M. Schütte, "Mathematics education and language: Lessons and directions from two decades of research " in Developing research in mathematics education. Twenty years of communication, cooperation and collaboration in Europe (T. Dreyfus, M. Artigue, D. Potari, S. Prediger \& K. Ruthven eds.), 196-210, New York: Routledge, 2018.

[19] NCTM (National Council of Teachers of Mathematics), "Cartoon Corner: Humor-Based Mathematics Activities" (Edited by A. Reeves). Reston, VA: National Council of Teachers of Mathematics, 2007.

[20] NCTM (National Council of Teachers of Mathematics), "Cartoon Corner 2: Humor-Based Mathematics Activities" (Edited by P. House). Reston, VA: National Council of Teachers of Mathematics, 2013.

[21] R. A Stein, Engle, M. S. Smith \& E. K. Hughes, "Orchestrating Productive Mathematical Discussions: Five Practices for Helping Teachers Move Beyond Show and Tell", Thinking and Learning, vol. 10, no. 4, pp. 313-340, 2008. 